\title{
Protective effect of Danggui (Radix Angelicae Sinensis) on angiotensin Il-induced apoptosis in H9c2 cardiomyoblast cells
}

\author{
Chih-Yang Huang ${ }^{1,2,3}$, Wei-Wen Kuo ${ }^{4}$, Chia-Hua Kuo ${ }^{5}$, Fuu-Jen Tsai ${ }^{1}$, Peng-Yu Liu ${ }^{1}$ and Dennis Jine-Yuan Hsieh ${ }^{6,7^{*}}$
}

\begin{abstract}
Background: Danggui (Radix Angelicae Sinensis) is an herb often used in Traditional Chinese medicine. It is used to promote blood flow and has been used in the treatment of myocardial ischemia-reperfusion injury in animal models. Angiotensin II (Ang II) has been shown to play important roles in mediating cardiovascular diseases, and may cause cardiac hypertrophy and apoptosis. This study aimed to investigate whether Danggui has protective effects on Ang II-induced apoptosis in H9c2 cardiomyoblast cells and study the mechanisms involved.

Methods: We evaluated the effect of Danggui on Ang II-induced apoptosis in an in vitro model. H9c2 cardiomyoblast cells were cultured in serum-free medium for $4 \mathrm{hr}$, then treated with Danggui (50, $100 \mathrm{\mu g} / \mathrm{ml}) 1 \mathrm{hr}$ pre- or post-Ang II treatment. After a further $23 \mathrm{hr}$ of culture, cells were harvested for analyses with assays for apoptosis markers and cell signaling pathways.
\end{abstract}

Results: Our results showed that Ang II induced upregulation of pro-apoptotic Bad, instability of the mitochondria membrane potential, cytochrome $c$ release, caspase-9 and caspase-3 activation and cardiomyocyte apoptosis. Pre- or post-treatment with Danggui reversed all of the above Ang II-induced apoptotic effects in H9c2 cells. Furthermore, the JNK (SP600125) inhibitor completely blocked Danggui inhibition of caspase-3 activation in Ang II-treated H9c2 cells.

Conclusions: Our results showed that Danggui either pre-treatment or post-treatment highly attenuated the Ang Il-induced apoptosis in cardiomyoblast cells. The findings demonstrated that the anti-apoptosis effect of Danggui is mediated by JNK and PI3K inhibitors.

Keywords: Traditional Chinese Medicine (TCM), Danggui, Radix Angelicae Sinensis, Angiotensin II, Cardiomyoblast, Apoptosis

\section{Background}

Cardiovascular disease is a major public health threat for both men and women in many countries. It remains the leading cause of death and disability worldwide. Many factors, such as metabolic syndrome, diabetes mellitus and hypertension, contribute to cardiovascular disease. Several clinical studies have reported that metabolic alterations in diabetes mellitus are associated with modification of growth hormone $(\mathrm{GH})$ and insulin-like growth factor-I (IGF-I) synthesis [1] and may play a role

\footnotetext{
*Correspondence: djh@csmu.edu.tw

${ }^{6}$ School of Medical Laboratory and Biotechnology, Chung Shan Medical University, No.110, Sec.1, Jianguo N. Rd., Taichung 40201, Taiwan ${ }^{7}$ Clinical Laboratory, Chung Shan Medical University Hospital, Taichung, Taiwan

Full list of author information is available at the end of the article
}

in the pathogenesis of heart failure [2]. In addition, IGF-II and IGF-II receptor (IGF-IIR) have been shown to be associated with the development of cardiac hypertrophy [3-6].

Patients with diabetes often show reduced circulating levels of IGF-I and thus develop IGF-I resistance [7,8]. This situation may induce apoptosis of myocardial cells and increase the risk of a heart attack. Studies in our laboratory have shown that the mechanism of apoptosis is synergistically mediated by angiotensin II- (Ang II) and the IGF-IR resistance-activated IGF-IIR signaling pathway $[5,9]$. This suggests that IGF-IIR and its downstream signaling are important in myocardial apoptosis, and suppression of IGF-IIR signaling pathways can protect myocardial cells from apoptosis. 
When the heart receives external stimulation, myocardial cells secrete Ang II [10,11], which may lead to hypertrophy and apoptosis of the cells [12,13]. Previously, by using an in vitro myocardial cell culture and an animal hypertension model (by abdominal aorta ligation resulting in an elevation in Ang II), we found that Ang II induces IGF-II and IGF-IIR gene expression that is mediated by JNK and ERK activation, and sequentially, IGF-IIR induces Goq, PKC- $\alpha / \mathrm{CaMKIIc}$ and calcineurin activation [9]. The IGF-II-stimulated myocardial cells tend towards pathological hypertrophy, as well as the activation of calcineurin/Bad, resulting in mitochondrialdependent apoptosis [5]. Many natural products such as herbs have been used in the treatment of heart disease. In this study, we focused on the IGF-IIR-associated pathway, and investigated whether inhibition of Ang II-induced cell damage can reduce cardiac apoptosis.

Radix Angelicae Sinensis (Danggui), the dried root of Angelica Sinensis, is an herb often used in Chinese food and Traditional Chinese medicine (TCM). Based on early Chinese medical literature, Danggui can promote blood flow and has been used to treat disorders with blood deficiency (for review see [14]). It is often used in the treatment of gynecological conditions that possess a blood deficiency pattern, such as dysmenorrhea and an irregular menstrual cycle. Danggui has also been reported to have an immunostimulatory effect in a mitogen-stimulated lymphocyte proliferation assay in a mouse model in vitro [15]. In addition, it has been shown to increase nitric oxide (NO) formation and vascular relaxation in the rat aorta [16]. It is often tied in with the $q i$ drugs (medicinals for treating disordered flow of $q i$, including stagnant flow and counterflow), used to treat the symptoms of blood stasis.

More than 70 compounds, including alkyl phthalides, benzenoids, butylphthalide, coumarins, flavones, organic acids, polysaccharides and trepenes, have been isolated from roots of Angelica sinensis. Among the identified main compounds, Z-ligustilide, phthalides and ferulic acid are known to be its major essential active components $[17,18]$. Modern research has also used Danggui extract for the treatment of myocardial ischemia-reperfusion injury in rats and found that it has a significant protective effect [19]. Meanwhile, the molecular pathway of Danggui in myocardial protection is still unclear and further studies are necessary to clarify the mechanisms underlying the effects of Danggui. Therefore, we speculated that Danggui may also have a protective effect against Ang II-induced myocardial apoptosis, and aimed to study the associated molecular signaling pathway.

\section{Methods}

\section{Danggui extract}

Danggui extract powder was provided by Ko Da Pharmaceutical (Taoyuan, Taiwan). After the powder was dissolved in double-distilled water completely, the solution was centrifuged and sterilized by filtering through a $0.2-\mu \mathrm{m}$ syringe filter and stored at $-80^{\circ} \mathrm{C}$.

\section{Cell culture and treatments}

H9c2 cardiomyoblasts were obtained from the American Type Culture Collection (ATCC) and cultured in Dulbecco's modified essential medium (DMEM) supplemented with $10 \%$ fetal bovine serum, $2 \mathrm{mM}$ glutamine, 100 units $/ \mathrm{ml}$ penicillin, $100 \mu \mathrm{g} / \mathrm{ml}$ streptomycin, and $1 \mathrm{mM}$ pyruvate in humidified air $\left(5 \% \mathrm{CO}_{2}\right)$ at $37^{\circ} \mathrm{C}$. To investigate the protective mechanisms of Danggui extract against cardiomyocyte apoptosis, H9c2 cardiomyoblast cells were cultured in serum-free medium for $4 \mathrm{hr}$, followed by treatment with Danggui extract (0, 50, 100, 250, 500 and $1000 \mu \mathrm{g} / \mathrm{ml}$ ) $1 \mathrm{hr}$ before or after Ang II treatment, respectively (Additional file 1: Figure S1). Cell lysate was collected for analysis $24 \mathrm{hr}$ after Ang II treatment.

\section{MTT (3-(4,5-Dimethylthiazol-2-yl)-2,5-diphenyltetrazolium bromide) assay}

In order to test the cytotoxicity of Danggui extract on H9c2 cardiomyoblast cells, H9c2 cells were treated with different concentrations of Danggui extract (0, 50, 100, $250,500,1000 \mu \mathrm{g} / \mathrm{ml}$ ) and the survival rate of H9c2 cells were measured by MTT assay (M5655, Sigma, St. Louis, MO, USA) according to the manufacturer's instructions.

\section{DAPI staining and TUNEL assay}

After treatment, $\mathrm{H} 9 \mathrm{c} 2$ cells were fixed with $4 \%$ paraformaldehyde solution for $30 \mathrm{~min}$ at room temperature, and permeabilized with $0.1 \%$ Triton X-100 for 2 min. Following washing with PBS, samples were first incubated with Terminal Deoxynucleotide Transferase-mediated dUTP Nick End Labeling (TUNEL) (11684817910, Roche, Mannheim, Germany) reagent containing terminal deoxynucleotidyl transferase and fluorescent isothiocyanate-dUTP. The cells were also counterstained with $1 \mu \mathrm{g} / \mathrm{ml}$ DAPI for $30 \mathrm{~min}$. Samples were analyzed under a fluorescence microscope. All morphometric measurements were performed using at least three independent individual samples in a blinded manner.

\section{JC-1 staining}

JC-1 (5, 5', 6, 6'-tetrachloro-1, 1', 3, 3'-tetraethylbenzimidazol-carbocyanine iodide) is a lipophilic fluorescent cation that is incorporated into the mitochondrial membrane, where it can form aggregates due to the state of the physiological membrane potential of the mitochondria. This aggregation changes the fluorescence properties of JC-1, leading to a shift from green to orange fluorescence. Intact living cells stained with $\mathrm{JC}-1$ therefore exhibit a pronounced orange fluorescence of mitochondria, which can be detected by confocal microscopy. Apoptosis results 
in breakdown of the mitochondrial membrane potential and a subsequent decrease of the orange fluorescence (and a slight increase of the green fluorescence). By this means, apoptotic cells can be easily distinguished from non-apoptotic cells. In brief, after treatment, cells were washed with PBS and incubated with medium containing JC-1 staining reagent at $37^{\circ} \mathrm{C}$ for $20 \mathrm{~min}$ followed by washing with PBS. The mitochondrial membrane potential was detected by confocal microscopy.

\section{Western blot analysis}

Cell lysates were separated by $8-12 \%$ gradient SDS-PAGE and transferred onto nitrocellulose membrane. The membrane was blocked in 5\% milk for $1 \mathrm{hr}$, and blotted with primary antibody at $4^{\circ} \mathrm{C}$ overnight. After incubation with secondary antibody for $2 \mathrm{hr}$ at room temperature, the protein bands were detected by enhanced chemiluminescence (ECL, Santa Cruz Biotechnology, Santa Cruz, CA, USA). Densitometric analysis of immunoblots was performed using the LAS-3000 imaging system (Fuji Photo Film, Tokyo, Japan). PI3k antibody (610064) was obtained from BD Biosciences (San Jose, CA, USA), p-Akt (44-622) and p-ERK1/2 (44-680) antibodies were obtained from Biosource Int. (Camarillo, CA, USA), p-Bad antibody (9296) was obtained from Cell Signaling Technology (Beverly, MA, USA) and IGF-II antibody (ab63984) was obtained from Abcam Incorporated (Cambridge, MA, USA). Other monoclonal antibodies were purchased from Santa Cruz Biotechnology (Santa Cruz).

\section{Inhibitors}

H9c2 cells were treated with several inhibitors, including U0126 (MEK1 and MEK2 inhibitor, \#V1121, Promega, Madison, WI, USA) and SP600125 (JNK inhibitor) (\#1496, TOCRIS /Ellisville, MO, USA).

\section{Statistical analysis}

Statistical differences were assessed by one way-ANOVA using the Duncan test for comparison between groups. $P<0.05$ was considered statistically significant. Data were expressed as the mean \pm SEM.

\section{Results}

\section{Effects on the cell viability of cells treated with Ang II}

Pre-treatment with Danggui extract at a concentration of $250 \mu \mathrm{g} / \mathrm{ml}$ or higher showed an attenuating effect on Ang II-induced cell death (Figure 1A), while post-treatment with Danggui extract also reduced the cell death, but had a lesser effect than pre-treatment (Figure 1B). We also analyzed the cytotoxicity of Danggui extract on H9c2 cells, and found that Danggui extract has no cytotoxic effect on $\mathrm{H} 9 \mathrm{c} 2$ cells at concentrations up to $500 \mu \mathrm{g} / \mathrm{ml}$, but may cause obvious cell death at concentrations higher than $500 \mu \mathrm{g} / \mathrm{ml}$ after $24 \mathrm{hr}$ of incubation (data not shown).

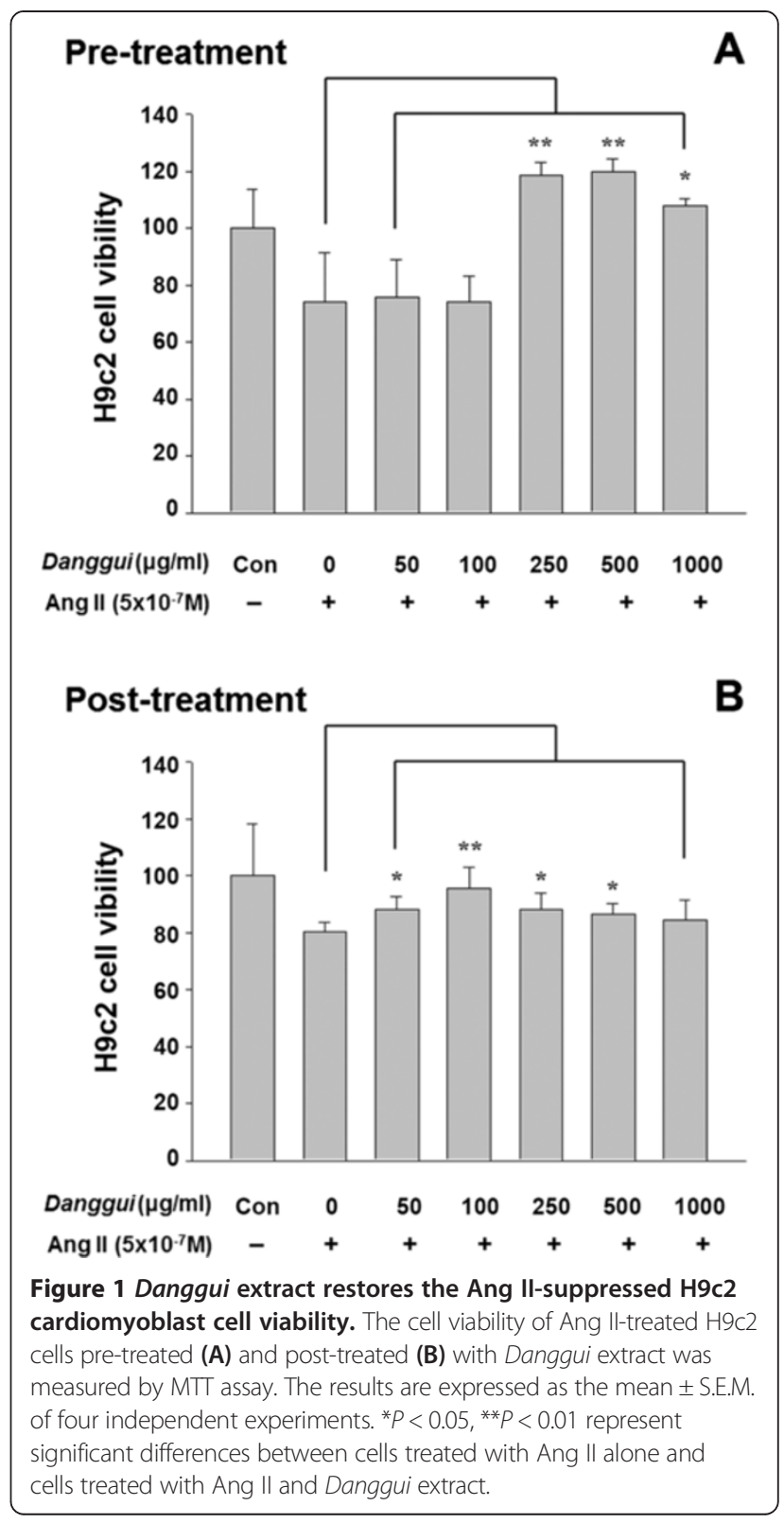

Based on this result, we used Danggui extract in the range of $50-500 \mu \mathrm{g} / \mathrm{ml}$ in the following experiments.

\section{Inhibition of Ang II-induced H9c2 cardiomyoblast apoptosis and DNA fragmentation}

The results of DAPI staining showed that Ang II treatment induced apoptosis in $\mathrm{H} 9 \mathrm{c} 2$ cells, while pre-treatment or post-treatment with Danggui extract (50 to $500 \mu \mathrm{g} / \mathrm{ml}$ ) resulted in a significant decrease of Ang II-induced apoptosis (Figure 2). This result suggested that Danggui extract has an inhibition effect against Ang II- induced apoptosis in $\mathrm{H} 9 \mathrm{c} 2$ cardiomyoblast cells.

We then used a TUNEL assay to analyze the apoptosis level in H9c2 cells with a DAPI counterstain to calculate 

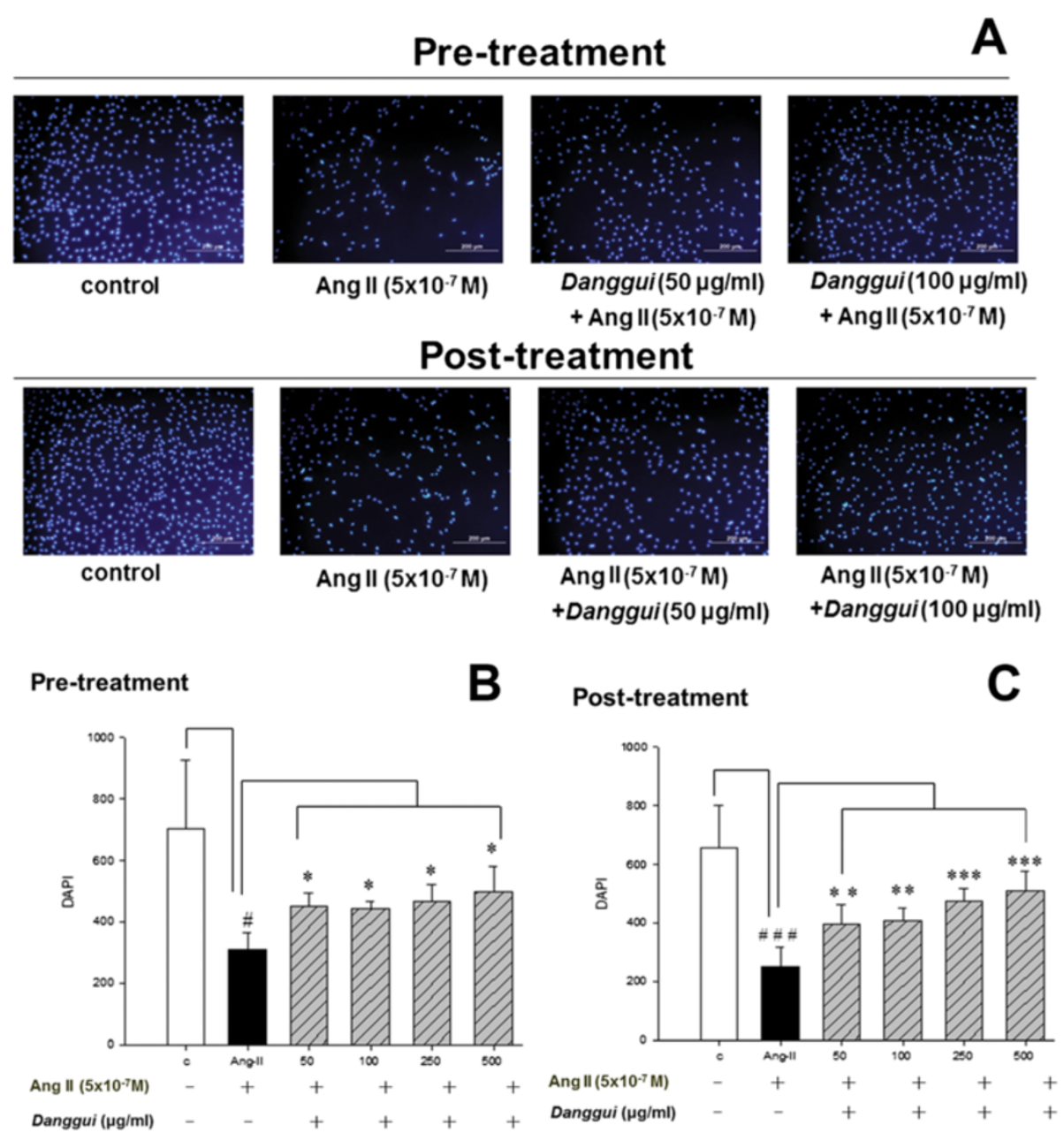

Figure 2 Danggui extract inhibits the Ang II-induced H9c2 cardiomyoblast cells apoptosis. (A) Influence of pre-treatment or post-treatment with Danggui extract on Ang II-induced H9c2 cardiomyoblast apoptosis. The blue spot indicates DAPI staining representing the cell number. Percentage of apoptotic cells following pre-treatment (B) or post-treatment (C) with Danggui extract in the control and Ang II-treated H9c2 cells. The results are expressed as the mean \pm S.E.M. of four independent experiments. ${ }^{\#} P<0.05$, ${ }^{\# \#} P<0.001$ between the controls and cells treated with Ang II alone. ${ }^{*} P<0.05,{ }^{* *} P<0.01,{ }^{* *} P<0.001$ between cells treated with Ang II alone and cells treated with Ang II and Danggui extract.

the total cell number. The result showed that the number of apoptotic bodies was increased with Ang II treatment, and was significantly decreased with pre-treatment or posttreatment with Danggui extract (at as low as $50 \mu \mathrm{g} / \mathrm{ml}$ ) (Figure 3).

\section{Inhibition of Ang II-induced caspase-9 and caspase-3 activation}

To investigate the involvement of caspases in Ang II-induced cell death, we performed Western blotting analysis of caspase- 9 and caspase-3. As shown in Figure 4, the protein levels of active caspase- 9 and caspase- 3 were increased with Ang II treatment, and were significantly decreased following both pre-treatment and post-treatment with Danggui extract in H9c2 cells. This suggests that Danggui extract can downregulate the mitochondrial death pathway to inhibit the apoptosis induced by Ang II. All the Western data are quantified and the results are showed in Supplementary data (Additional file 1: Figure S2).

Rescue effect on the Ang II-induced instability of the mitochondria membrane potential and cytochrome $c$ release

In order to validate the involvement of the mitochondrial death pathway in $\mathrm{H} 9 \mathrm{c} 2$ cells after Ang II treatment, the mitochondrial membrane potential was assessed by JC-1 staining. The result demonstrated that Ang II caused the mitochondria membrane potential to become more unstable (Figure 5A) and led to cytochrome $c$ release (Figure 5B). However, when Ang II-treated H9c2 cells were pre-treated or post-treated with Danggui extract, 

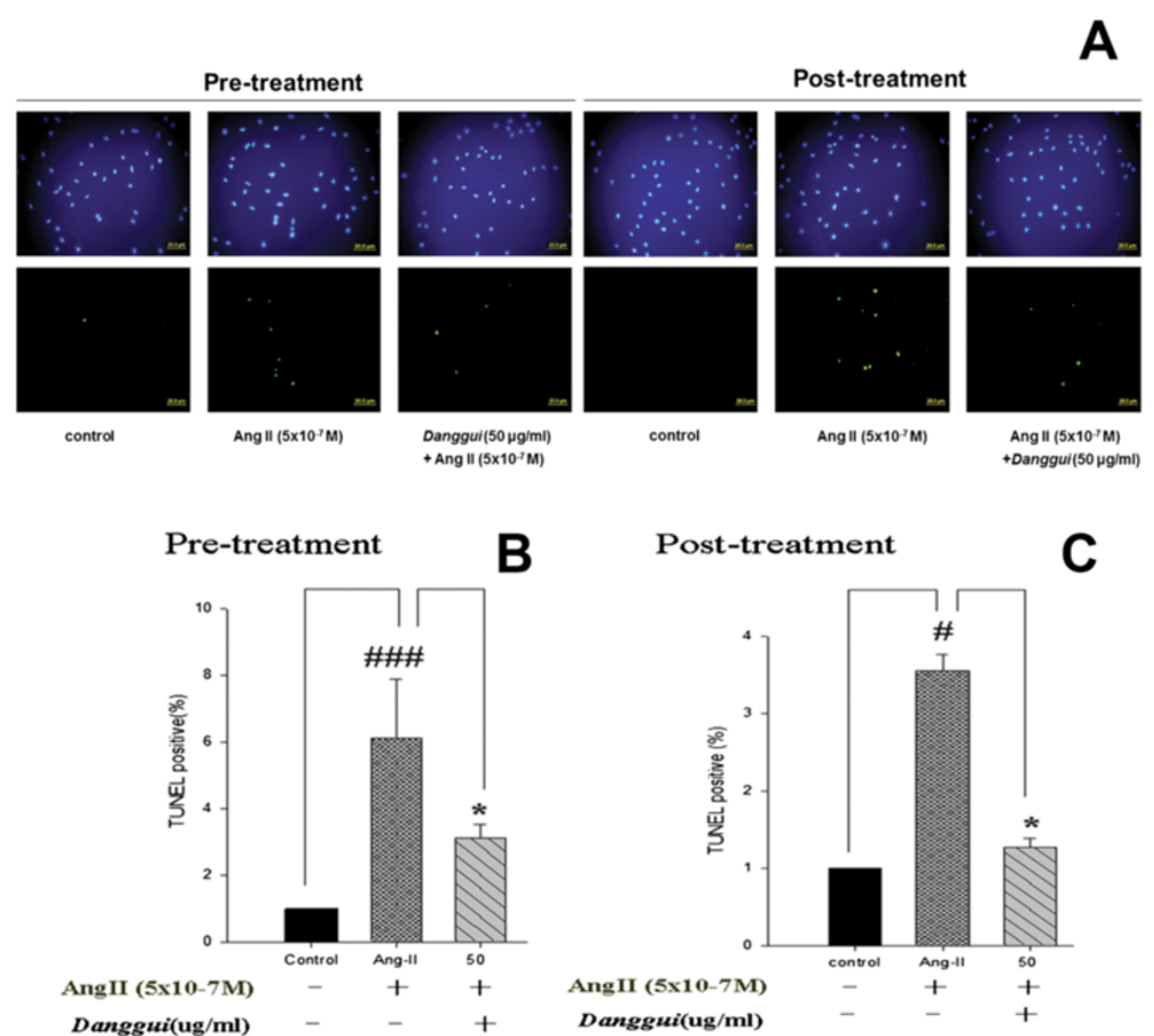

Figure 3 Danggui extract inhibits Ang II-induced DNA fragmentation in H9c2 cardiomyoblast cells. (A) Effect of pre-treatment or post-treatment with Danggui extract on Ang II-induced H9c2 cardiomyoblast apoptosis. The blue spot indicates DAPI counterstaining representing the cell number, and the green spot represents the apoptotic cells stained by TUNEL assay. Percentage of apoptotic cells following pre-treatment (B) or post-treatment (C) with Danggui extract in Ang II-induced H9c2 cells. The results are expressed as the mean \pm S.E.M. of four independent experiments. ${ }^{\#} P<0.05$,

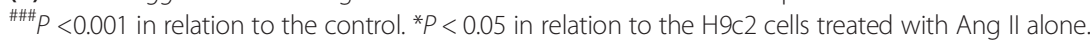

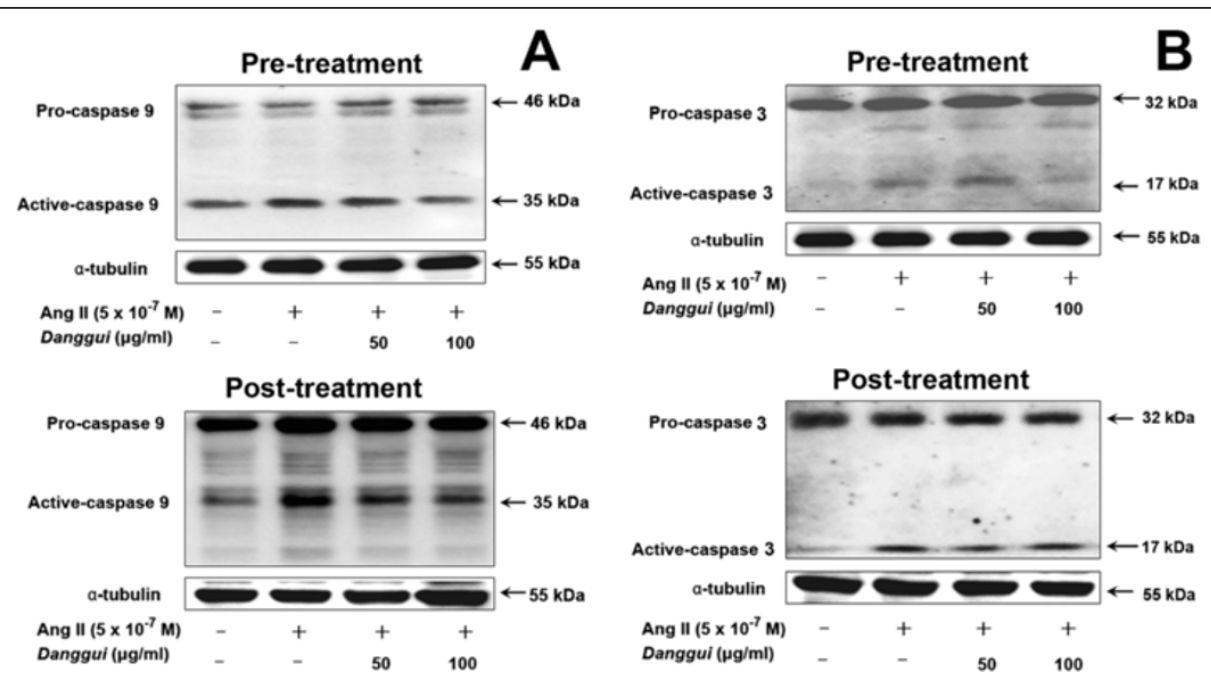

Figure 4 Danggui extract inhibits Ang Il-induced caspase 9 (A) and caspase 3 (B) activation in H9c2 cardiomyoblast cells. H9c2 cells were treated with Ang II $\left(5 \times 10^{-7} \mathrm{M}\right)$ for $1 \mathrm{hr}$, and then treated with Danggui extract $(50,100 \mathrm{\mu g} / \mathrm{ml})$ either $1 \mathrm{hr}$ before (pre-treatment) or $1 \mathrm{hr}$ after (post-treatment) Ang II treatment, followed by another $23 \mathrm{hr}$ of culture. Cells were harvested and extracted for Western blotting analysis. a-tubulin was employed as the internal control. 

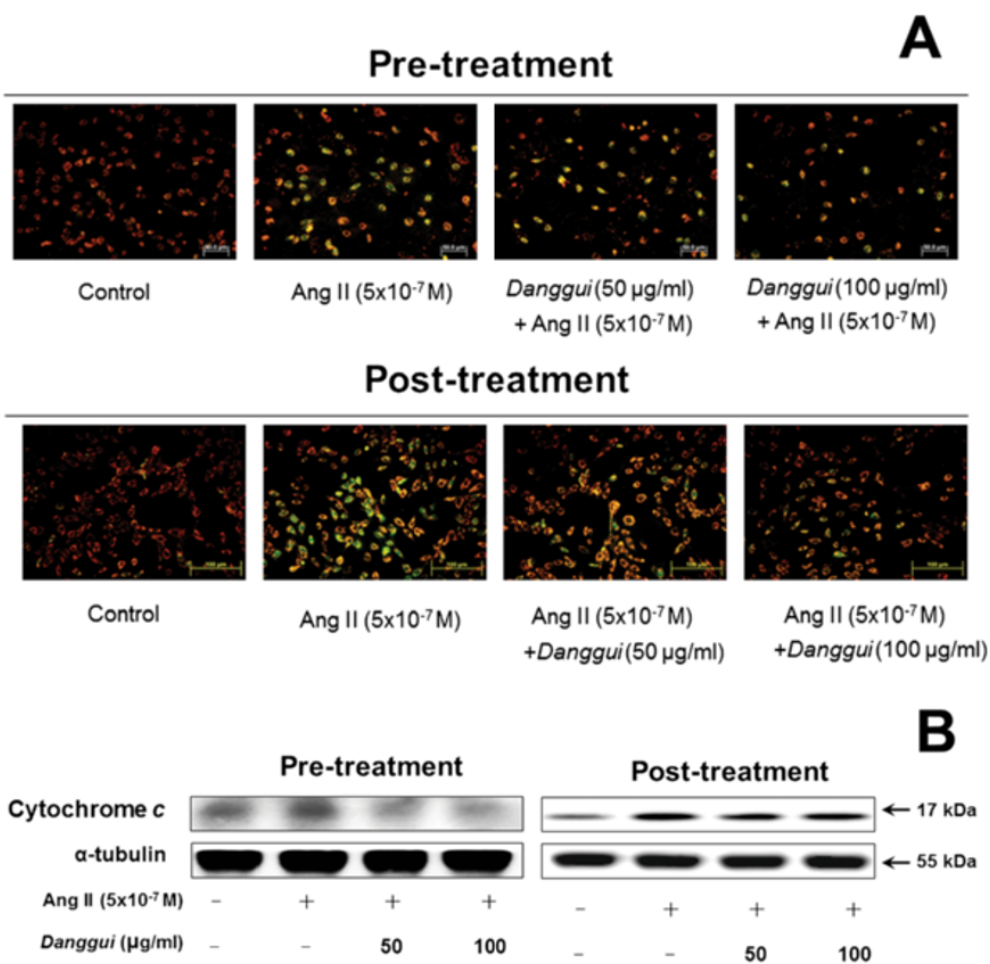

Figure 5 Danggui extract reverses the Ang II-induced instability of the mitochondria membrane potential and cytochrome $c$ expression. (A) Ang II induced instability of the mitochondria membrane potential, as detected by Fluorescein isothiocyanate- (FITC-) JC-1 staining in H9c2 cells. The red image represents that the stable state of Danggui extract could stabilize the mitochondria membrane potential and the green image shows the cells in an unstable state. (B) $\mathrm{H} 9 \mathrm{c} 2$ cells were treated with Ang $\|\left(5 \times 10^{-7} \mathrm{M}\right)$ for $1 \mathrm{hr}$, and then treated with Danggui extract $(50,100 \mu \mathrm{g} / \mathrm{ml})$ either $1 \mathrm{hr}$ before (pre-treatment) or $1 \mathrm{hr}$ after (post-treatment) Ang II treatment, followed by another $23 \mathrm{hr}$ of culture. The protein expression of cytochrome $c$ was assessed by Western blotting. a-tubulin was employed as the internal control.

the mitochondria membrane potential stabilized and the release of the mitochondria membrane protein cytochrome $c$ decreased (Figure 5).

Signaling mechanism of the anti-apoptosis effect in H9c2 cardiomyoblast cells

To understand the mechanism controlling mitochondrial permeability, we analyzed Bcl-2 family proteins, which are key regulators and may be involved in the apoptosis of cardiomyoblast cells. Our results showed that the levels of anti-apoptotic proteins phosphorylated $\mathrm{Bad}$ (p-Bad) and Bcl- $\mathrm{x}_{\mathrm{L}}$ were decreased by Ang II treatment, and pre- or post-treatment with Danggui extract rescued the expressions of $\mathrm{Bad}(\mathrm{p}-\mathrm{Bad})$ and $\mathrm{Bcl}-\mathrm{x}_{\mathrm{L}}$ (Figure 6A). These results indicated the anti-apoptotic potential of Danggui extract, which contributes to stabilizing the mitochondria membrane potential through regulating related proteins against apoptosis.

In order to elucidate whether Danggui extract inhibits apoptosis by activating the cardiac IGF-I survival pathway, phosphatidylinositol 3-kinase (PI3k) and Akt kinase (Akt) proteins were analyzed by Western blot. It was found that the phosphorylated PI3k (p-PI3k) and phosphorylated Akt (p-Akt) protein levels were greatly decreased by Ang II, but the protein levels could be recovered by both pre-treatment and post-treatment treatment with Danggui extract in H9c2 cells (Figure 6B).

The chemical inhibitors JNK (SP600125) and MEK (U0126) were applied to investigate the mediator for Danggui extract-attenuated Ang II-stimulated caspase-3 activation. The results showed that the JNK inhibitor (SP600125) totally blocked Danggui extract-inhibited caspase-3 activation in Ang II-treated H9c2 cells, but the MEK inhibitor (U0126) did not (Figure 6C).

\section{Discussion}

Danggui is a key herb in several herbal formulas that are used to treat several diseases. These Danggui-containing formulas, such as Danggui Buxue Decoction, have been shown to have an antioxidant effect [20,21]. Danggui has also been shown to promote angiogenesis [22]. Danggui is not only commonly used to treat various gynecological conditions, but recent studies have also shown that it can prevent doxorubicin-induced chronic cardiotoxicity and reduce myocardial injury in animal models [23,24]. A range of active compounds have already been isolated and identified from Danggui [17]. Among the identified main compounds, Z-ligustilide, phthalides and ferulic 

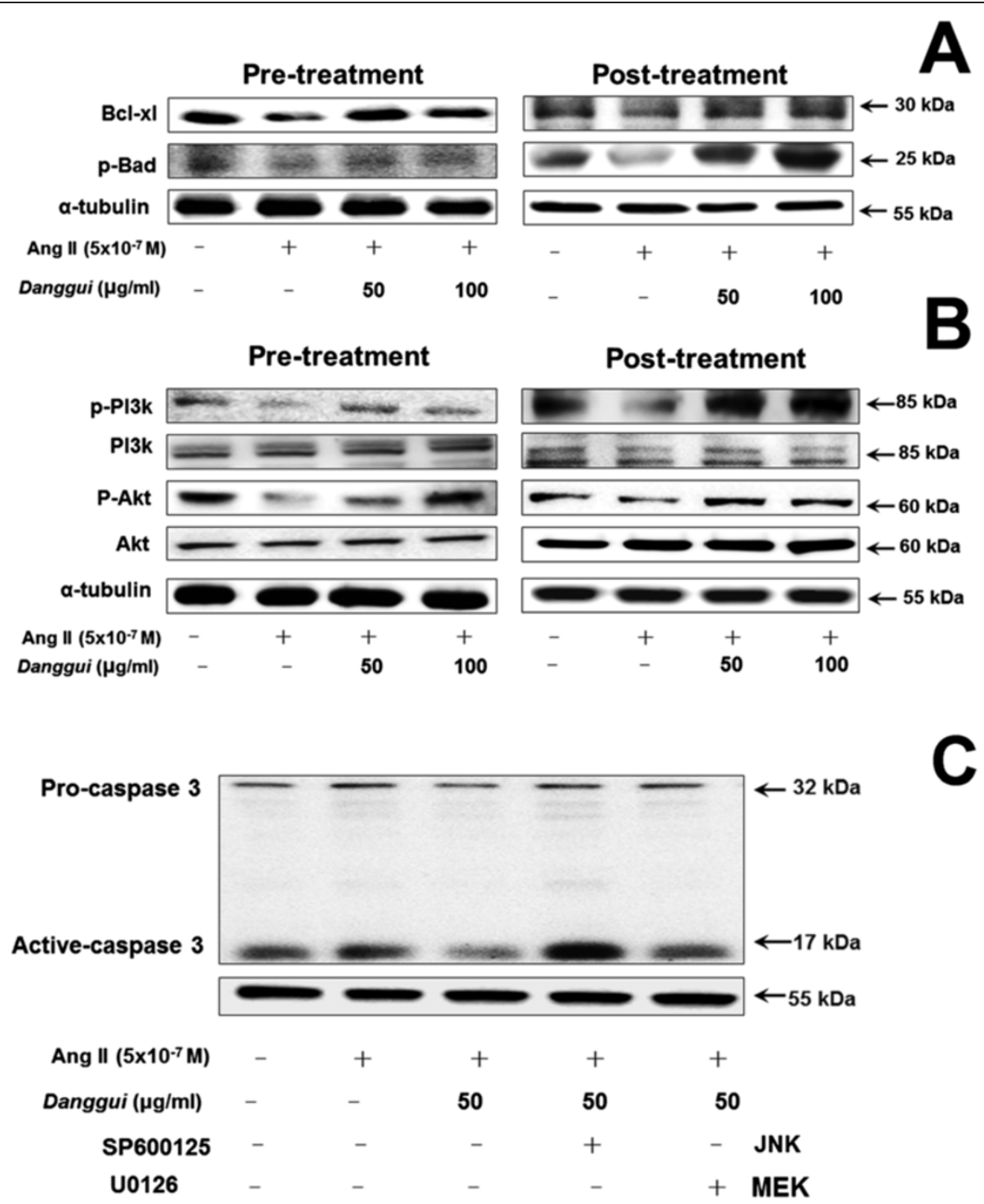

Figure 6 Danggui extract reversed the Ang II-reduced cardiac survival pathway in H9c2 cardiomyoblast cells. H9c2 cells were treated with Ang $\|\left(5 \times 10^{-7} \mathrm{M}\right)$ for $1 \mathrm{hr}$, and then treated with Danggui extract $(50,100 \mathrm{\mu g} / \mathrm{ml})$ either $1 \mathrm{hr}$ before (pre-treatment) or $1 \mathrm{hr}$ after (post-treatment) Ang $\|$ treatment, followed by another $23 \mathrm{hr}$ of culture. Western blotting analysis of (A) BCl-X and p-Bad expressions, and (B) p-PI3K, PI3K, p-Akt and Akt. (C) pro-caspase-3 and caspase-3 expression in H9c2 cells treated with inhibitors U0126 (MEK1 and MEK2 inhibitor) and SP600125 (JNK inhibitor). a-tubulin was used as the internal control.

acid are known to be its major essential active components $[17,18]$.

Ang II has been shown to be a risk factor for cardiovascular diseases, as it has been reported to cause cardiac hypertrophy and apoptosis. Our previous study demonstrated that Ang II may evoke IGF-II and IGF-IIR through the ERK and JNK signaling pathways, and further activates cardiac cell apoptosis via calcineurin-dependent pathways [9]. This might be the key step that causes heart failure. Furthermore, a study performed in our laboratory demonstrated that pathological hypertrophic stimulus, including Ang II, up-regulates the IGF-IIR gene expression in H9c2 cells, and histone acetylation plays a critical role in IGF-IIR up-regulation [25]. We also noticed that the Ang II-induced IGF-IIR gene expression can be reversed by Danggui treatment (data not shown). Thus, we speculated that Danggui may prevent the Ang II-induced damage in cells.

MTT assay showed that Danggui extract has no cytotoxic effect on H9c2 cells at concentrations up to $500 \mu \mathrm{g} / \mathrm{ml}$. Ang II administration caused a significant decrease in the cell viability (Figure 1), which is in agreement with the results of another study [26]. Ang II has been shown to inhibit the IGF-IR signaling pathway and activate the IGF- 
IIR signaling pathway in damaged $\mathrm{H} 9 \mathrm{c} 2$ cells $[9,27]$. The results of the current study showed that Danggui extract at a concentration between 100 and $500 \mu \mathrm{g} / \mathrm{ml}$ prevents the H9c2 cell damage caused by Ang II treatment.

It has been shown previously that cell survival is decreased in Ang II-treated H9c2 cells [27], and in this study, we showed that pre-treatment or post-treatment with Danggui extract significantly protected H9c2 cells from Ang II-induced apoptosis. Furthermore, the effects of pre- and post-treatment with Danggui extract on Ang II-induced H9c2 cells apoptosis were both effective and dose-dependent (Figure 2B). These results suggested that Danggui extract has a highly protective effect against Ang II-induced apoptosis. Ang II stimulation induces apoptosis of ventricular myocytes in several animal models $[28,29]$. The results of a TUNEL assay supported that apoptotsis induced by Ang II treatment was significantly inhibited by both pre-treatment and posttreatment with Danggui extract.

Ang II activates calcium-calmodulin-dependent protein phosphatase calcineurin through Galphaq (Go-q)/PLC signaling transduction $[27,30]$. $\mathrm{Ca}^{2+} /$ calcineurin also dephosphorylates pro-apoptotic Bcl-2 family protein Bad and induces cytochrome $c$ release from mitochondria to the cytosol, which further induces caspase activation and cardiac cell apoptosis [27,31]. We showed that Ang II stimulation causes apoptosis and induces caspase-9 and caspase-3 activation (Figure 4). When cells were pretreated with Danggui extract, the protein levels of active caspase- 9 and caspase- 3 were both significantly decreased at a concentration of $100 \mu \mathrm{g} / \mathrm{ml}$. Post-treatment with
Danggui extract still resulted in a significant decrease in the active caspase- 9 level.

Furthermore, it was found that Danggui extract can block Ang II-induced mitochondria membrane potential instability and cytochrome $c$ release. In addition, the effect of pre-treatment with Danggui extract was more obvious than that of post-treatment. These findings suggest that the protective effect of Danggui extract is mediated by stabilization of the mitochondria membrane potential and inhibition of cytochrome $c$ release against Ang II-induced caspase- 9 and caspase- 3 activation and cell apoptosis. This study reports for the first time that Danggui extract treatment significantly reduces Ang II-induced myocyte apoptosis as indicated by the reduction in caspase- 9 and caspase- 3 activity.

An earlier study showed that retinoic acid improved mitochondrial function by inhibiting the mechanical damage and Ang II-induced reduction in the mitochondrial membrane potential, cytochrome $c$ release, and by increasing the $\mathrm{Bcl}-2 / \mathrm{Bax}$ ratio [32]. In addition, previous studies have demonstrated that JNK can suppress apoptosis in IL-3-dependent hematopoietic cells via phosphorylation of the pro-apoptotic Bcl-2 family protein Bad [33], and prevents inactivation of the pro-survival Bcl-2 family protein $\mathrm{Bcl}-\mathrm{x}_{\mathrm{L}}$ by $\mathrm{Bad}$ [34]. The results of this study revealed that anti-apoptotic proteins $\mathrm{p}-\mathrm{Bad}$ and $\mathrm{Bcl}-\mathrm{x}_{\mathrm{L}}$ were decreased by Ang II treatment, and the levels of p-Bad and $\mathrm{Bcl}-\mathrm{x}_{\mathrm{L}}$ were significantly increased after pre- or posttreatment with Danggui extract (Figure 6A). These findings indicate that the anti-apoptotic potential of Danggui extract is mediated by stabilizing the mitochondrial

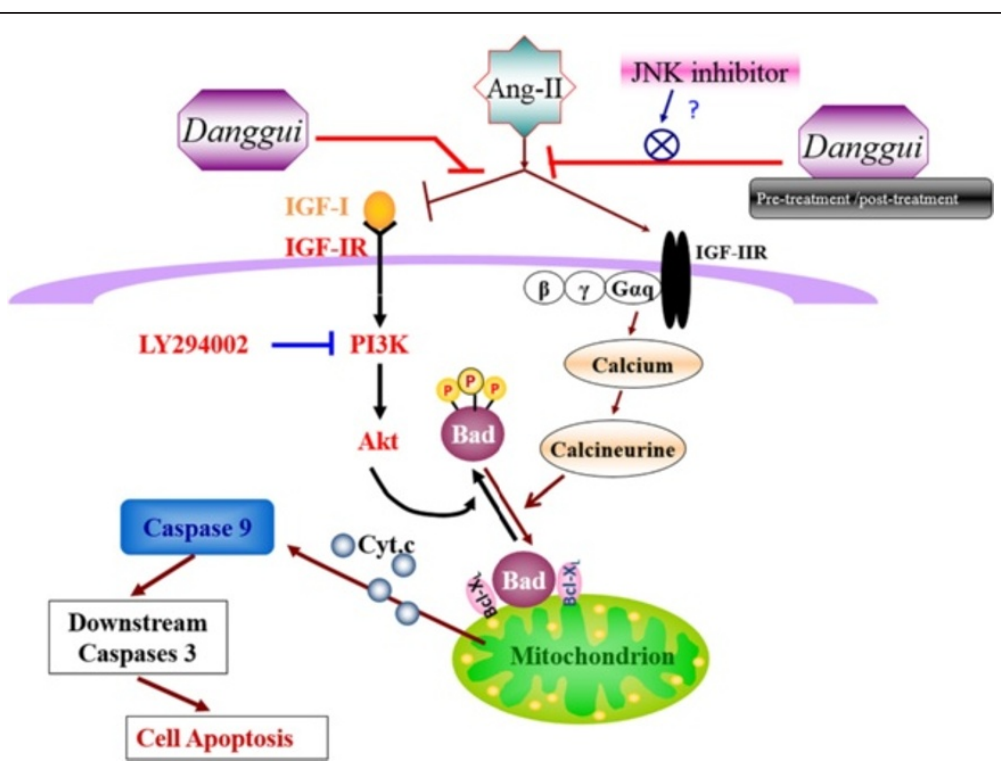

Figure 7 Schematic diagram. Possible mechanism of Danggui-associated inhibition of the mitochondrial-dependent apoptosis pathway induced by Ang II in $\mathrm{H} 9 \mathrm{c} 2$ cardiomyoblast cells. 
membrane potential through regulating anti-apoptotic proteins against apoptosis.

Kuo and colleagues [27] reported that IGF-I/IGF-IR via intracellular signaling pathways involving tyrosine kinase activity may exert an anti-apoptotic effect via PI3k and Akt-dependent Bad phosphorylation (p-Bad). Therefore, the IGF-I/IGF-IR signaling pathway may play an important role in the Ang II-reduced cardiac survival pathway in H9c2 cells. To clarify whether Danggui extract inhibition of apoptosis is mediated by activating this pathway, the levels of p-PI3k and p-Akt were analyzed. Our results demonstrated that the Ang II-induced decreased expressions of these proteins were recovered with both pretreatment and post-treatment with Danggui extract. In addition, angiotensin converting enzyme inhibitor might increase the IGF-I concentration [35] and Ang II might decrease circulating IGF-I in rats [36]. Ang II reduces the IGF-I-stimulated sodium pump activity by attenuating PI3k/Akt signaling in vascular smooth muscle cells [37]. Therefore, we hypothesized that Ang II may block IGF-I expression or enhance IGF-I resistance and inhibit the IGF-IR-mediated PI3k-Akt signaling pathway to induce H9c2 cell apoptosis, which may recover following treatment with Danggui extract (Figure 7). We also found that in the cells co-stimulated with Ang II and Danggui, SP600125 inhibited JNK activity (decreased the proapoptotic response) and activated p-PI3k and p-Akt (increased the anti-apoptotic effect). However, SP600125 alone or treatment with Ang II and Danggui both increased the active caspase- 3 expression (Additional file 1: Figure S3). The reason for SP600125 (JNK inhibitor) to increase p-Akt activity is still not clear. However, similar finding has been reported in rat granule neurons [38].

As IGF-II and IGF-IIR also play critical roles in Ang II-induced apoptosis in H9c2 cells, it is critical to know which signaling pathways are involved in the Danggui extract-mediated protective effect. The JNK inhibitor (SP600125) can block Ang II-induced IGF-IIR expression and apoptosis [9], suggesting that JNK activation mediates Ang II-induced apoptosis. However, the results of the present study also showed that the JNK inhibitor (SP600125) can completely block the inhibition by Danggui extract of caspase-3 activation in Ang II-treated H9c2 cells, but the MEK inhibitor (U0126) does not. This indicates that JNK activation mediates the protective effect of Danggui extract. Besides, many previous studies have shown that JNK activation mediates antiapoptotic effects $[33,34,39]$. Taken together, these findings and the results of this study suggest that JNK activation has a dual pro-apoptotic and anti-apoptotic effect on Ang II- and Danggui extract-mediated cell viability, respectively, although the underlying molecular mechanism remains to be elucidated. Furthermore, to further investigate the importance of the JNK pathway in Danggui-protected
Ang II-induced IGF related cardiac apoptosis, we explored the role of the IGF-I/IGF-IR pathway in the Danggui extract-mediated protective effect. By Western blotting analysis, we examined the IGF II and IGF IIR expressions and the PI3K/AKT pathway after JNK inhibitor cotreatment with Danggui and Ang II treatment in H9c2cells (Additional file 1: Figure S3). Like the JNK inhibitor (SP600125), the PI3k inhibitor (LY294002) completely blocked the inhibition by Danggui extract of caspase- 3 activation in Ang II-treated H9c2 cells, but the IGF-IR inhibitor (AG1024) did not (Additional file 1: Figure S4). Consequently, according to the inhibitors assay, PI3k activation mediates the protective effect of Danggui extract.

\section{Conclusions}

In conclusion, the induction of downregulation of antiapoptotic p-PI3k, p-Akt and Bcl- $x_{\mathrm{L}}$, upregulation of proapoptotic Bad, instability of the mitochondria membrane potential, cytochrome $c$ release, caspase- 9 and caspase- 3 activation and cardiomyocyte apoptosis were observed after Ang II treatment. However, both pre- and posttreatment with Danggui extract reversed all of the Ang II-induced effects. We have provided herein the first evidence that Danggui can inhibit AngII-induced apoptosis, and JNK and PI3k inhibitors can block the anti-apoptosis effect of Danggui.

\section{Additional file}

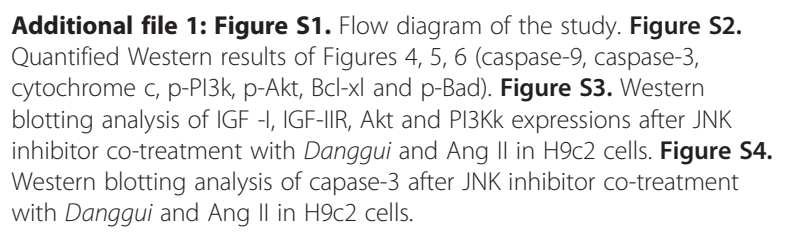

\section{Competing interests}

The authors declare that they have no competing interests. Danggui extract powder was provided by Ko Da Pharmaceutical. The company had no role in this study.

\section{Authors' contributions}

CYH, WWK, CHK, FJT and DJH contributed to the experimental design, data interpretation and editing of the manuscript. DJH and PYL participated in data acquisition, data analysis and interpretation, and preparation of the manuscript. All authors read and approved the final manuscript.

\section{Acknowledgements}

The authors thank Ko Da Pharmaceutical for providing Danggui extract powder and batch analysis results of the powder. This study was supported by the The Taiwan Ministry of Health and Welfare Clinical Trial and Research Center of Excellence (MOHW103-TDU-B-212-113002) and in part by China Medical University (CMU-95-176).

\section{Author details}

${ }^{1}$ Graduate Institute of Chinese Medical Science, China Medical University, Taichung, Taiwan. ${ }^{2}$ Graduate Institute of Basic Medical Science, China Medical University, Taichung, Taiwan. ${ }^{3}$ Department of Health and Nutrition Biotechnology, Asia University, Taichung, Taiwan. ${ }^{4}$ Department of Biological Science and Technology, China Medical University, Taichung, Taiwan. 
${ }^{5}$ Department of Sports Sciences, University of Taipei, Taipei, Taiwan. ${ }^{6}$ School of Medical Laboratory and Biotechnology, Chung Shan Medical University, No.110, Sec.1, Jianguo N. Rd., Taichung 40201, Taiwan. ${ }^{7}$ Clinical Laboratory, Chung Shan Medical University Hospital, Taichung, Taiwan.

Received: 11 April 2014 Accepted: 19 September 2014 Published: 25 September 2014

\section{References}

1. Tannenbaum GS: Growth hormone secretory dynamics in streptozotocin diabetes: evidence of a role for endogenous circulating somatostatin. Endocrinology 1981, 108:76-82

2. Castellano G, Affuso F, Conza PD, Fazio S: The GH/IGF-1 axis and heart failure. Curr Cardiol Rev 2009, 5:203-215.

3. Chang MH, Kuo WW, Chen RJ, Lu MC, Tsai FJ, Kuo WH, Chen LY, Wu WJ, Huang CY, Chu CH: IGF-II/mannose 6-phosphate receptor activation induces metalloproteinase-9 matrix activity and increases plasminogen activator expression in $\mathrm{H} 9 \mathrm{c} 2$ cardiomyoblast cells. J Mol Endocrinol 2008, 41:65-74.

4. Chu CH, Tzang BS, Chen LM, Kuo CH, Cheng YC, Chen LY, Tsai FJ, Tsai CH, Kuo WW, Huang CY: IGF-II/mannose-6-phosphate receptor signaling induced cell hypertrophy and atrial natriuretic peptide/BNP expression via Galphaq interaction and protein kinase C-alpha/CaMKII activation in H9c2 cardiomyoblast cells. J Endocrinol 2008, 197:381-390

5. Chu CH, Tzang BS, Chen LM, Liu CJ, Tsai FJ, Tsai CH, Lin JA, Kuo WW, Bau DT, Yao $\mathrm{CH}$, Huang CY: Activation of insulin-like growth factor II receptor induces mitochondrial-dependent apoptosis through $\mathrm{G}(\mathrm{alpha}) \mathrm{q}$ and downstream calcineurin signaling in myocardial cells. Endocrinology 2009, 150:2723-2731.

6. Hunter JJ, Chien KR: Signaling pathways for cardiac hypertrophy and failure. N Engl J Med 1999, 341:1276-1283.

7. Tappy L, Fujita-Yamaguchi Y, LeBon TR, Boden G: Antibodies to insulin-like growth factor I receptors in diabetes and other disorders. Diabetes 1988 37:1708-1714

8. Thrailkill KM: Insulin-like growth factor-l in diabetes mellitus: its physiology, metabolic effects, and potential clinical utility. Diabetes Technol Ther 2000, 2:69-80

9. Lee SD, Chu CH, Huang EJ, Lu MC, Liu JY, Liu CJ, Hsu HH, Lin JA, Kuo WW, Huang CY: Roles of insulin-like growth factor II in cardiomyoblast apoptosis and in hypertensive rat heart with abdominal aorta ligation. Am J Physiol Endocrinol Metab 2006, 291:E306-E314.

10. Lijnen $P$, Petrov V: Renin-angiotensin system, hypertrophy and gene expression in cardiac myocytes. J Mol Cell Cardiol 1999, 31:949-970.

11. Sernia C: A critical appraisal of the intrinsic pancreatic angiotensingenerating system. JOP 2001, 2:50-55.

12. Dostal DE, Baker KM: Angiotensin II stimulation of left ventricular hypertrophy in adult rat heart. Mediation by the AT1 receptor. Am J Hypertens 1992, 5:276-280.

13. Timmermans PB, Wong PC, Chiu AT, Herblin WF, Benfield P, Carini DJ, Lee RJ, Wexler RR, Saye JA, Smith RD: Angiotensin II receptors and angiotensin II receptor antagonists. Pharmacol Rev 1993, 45:205-251.

14. Wu YC, Hsieh CL: Pharmacological effects of Radix Angelica Sinensis (Danggui) on cerebral infarction. Chin Med 2011, 6:32.

15. Wilasrusmee C, Kittur S, Siddiqui J, Bruch D, Wilasrusmee S, Kittur DS: In vitro immunomodulatory effects of ten commonly used herbs on murine lymphocytes. J Altern Complement Med 2002, 8:467-475.

16. Rhyu MR, Kim JH, Kim EY: Radix angelica elicits both nitric oxide-dependent and calcium influx-mediated relaxation in rat aorta. J Cardiovasc Pharmacol 2005, 46:99-104

17. Chen XP, Li W, Xiao XF, Zhang LL, Liu CX: Phytochemical and pharmacological studies on Radix Angelica Sinensis. Chin J Nat Med 2013, 11:577-587.

18. Yi L, Liang $Y, W u H$, Yuan D: The analysis of Radix Angelicae Sinensis (Danggui). J Chromatogr A 2009, 1216:1991-2001.

19. Mak DH, Chiu PY, Dong TT, Tsim KW, Ko KM: Dang-Gui Buxue Tang produces a more potent cardioprotective effect than its component herb extracts and enhances glutathione status in rat heart mitochondria and erythrocytes. Phytother Res 2006, 20:561-567.

20. Li YD, Ma YH, Zhao JX, Zhao XK: Protection of ultra-filtration extract from Danggui Buxue Decoction on oxidative damage in cardiomyocytes of neonatal rats and its mechanism. Chin J Integr Med 2011, 17:854-859.
21. Chiu PY, Leung HY, Siu AH, Poon MK, Dong TT, Tsim KW, Ko KM: Dang-Gui Buxue Tang protects against oxidant injury by enhancing cellular glutathione in $\mathrm{H} 9 \mathrm{c} 2$ cells: role of glutathione synthesis and regeneration. Planta Med 2007, 73:134-141.

22. Meng H, Zhu MZ, Guo J, Sun JY, Pei JM, Huang C: [The study on angiogenesis activity of danggui, chuanxiong and danshen]. Zhong Yao Cai 2006, 29:574-576.

23. Xin YF, Zhou GL, Shen M, Chen YX, Liu SP, Chen GC, Chen H, You ZQ, Xuan $Y X$ : Angelica sinensis: a novel adjunct to prevent doxorubicin-induced chronic cardiotoxicity. Basic Clin Pharmacol Toxicol 2007, 101:421-426.

24. Zhang S, He B, Ge J, Li H, Luo X, Zhang H, Li Y, Zhai C, Liu P, Liu X, Fei X Extraction, chemical analysis of Angelica sinensis polysaccharides and antioxidant activity of the polysaccharides in ischemia-reperfusion rats. Int J Biol Macromol 2010, 47:546-550.

25. Chu CH, Lo JF, Hu WS, Lu RB, Chang MH, Tsai FJ, Tsai CH, Weng YS, Tzang BS, Huang CY: Histone acetylation is essential for ANG-II-induced IGF-IIR gene expression in $\mathrm{H} 9 \mathrm{c} 2$ cardiomyoblast cells and pathologically hypertensive rat heart. J Cell Physiol 2012, 227:259-268.

26. Pang JJ, Xu RK, Xu XB, Cao JM, Ni C, Zhu WL, Asotra K, Chen MC, Chen C: Hexarelin protects rat cardiomyocytes from angiotensin II-induced apoptosis in vitro. Am J Physiol Heart Circ Physiol 2004, 286:H1063-H1069.

27. Kuo WW, Liu CJ, Chen LM, Wu CH, Chu CH, Liu JY, Lu MC, Lin JA, Lee SD, Huang $\mathrm{CY}$ : Cardiomyoblast apoptosis induced by insulin-like growth factor (IGF)-I resistance is IGF-II dependent and synergistically enhanced by angiotensin II. Apoptosis 2006, 11:1075-1089.

28. Chen QM, Tu VC: Apoptosis and heart failure: mechanisms and therapeutic implications. Am J Cardiovasc Drugs 2002, 2:43-57.

29. Sharov VG, Todor A, Suzuki G, Morita H, Tanhehco EJ, Sabbah HN: Hypoxia, angiotensin-ll, and norepinephrine mediated apoptosis is stimulus specific in canine failed cardiomyocytes: a role for p38 MAPK, Fas-L and cyclin D1. Eur J Heart Fail 2003, 5:121-129.

30. Molkentin JD, Lu JR, Antos CL, Markham B, Richardson J, Robbins J, Grant $\mathrm{SR}$, Olson EN: A calcineurin-dependent transcriptional pathway for cardiac hypertrophy. Cell 1998, 93:215-228.

31. Wang HG, Pathan N, Ethell IM, Krajewski S, Yamaguchi Y, Shibasaki F, McKeon F, Bobo T, Franke TF, Reed JC: Ca2 +-induced apoptosis through calcineurin dephosphorylation of BAD. Science 1999, 284:339-343.

32. Choudhary R, Baker KM, Pan J: All-trans retinoic acid prevents angiotensin II- and mechanical stretch-induced reactive oxygen species generation and cardiomyocyte apoptosis. J Cell Physiol 2008, 215:172-181.

33. Liu J, Lin A: Role of JNK activation in apoptosis: a double-edged sword. Cell Res 2005, 15:36-42.

34. Zha J, Harada H, Yang E, Jockel J, Korsmeyer SJ: Serine phosphorylation of death agonist $B A D$ in response to survival factor results in binding to 14-3-3 not BCL-X(L). Cell 1996, 87:619-628.

35. Onder G, Penninx BW, Balkrishnan R, Fried LP, Chaves PH, Williamson Carter C, Di Bari M, Guralnik JM, Pahor M: Relation between use of angiotensin-converting enzyme inhibitors and muscle strength and physical function in older women: an observational study. Lancet 2002, 359:926-930.

36. Brink M, Wellen J, Delafontaine P: Angiotensin II causes weight loss and decreases circulating insulin-like growth factor I in rats through a pressor-independent mechanism. J Clin Invest 1996, 97:2509-2516.

37. Isenovic ER, Meng Y, Jamali N, Milivojevic N, Sowers JR: Ang II attenuates IGF-1-stimulated $\mathrm{Na}+, \mathrm{K}(+)$-ATPase activity via PI3K/Akt pathway in vascular smooth muscle cells. Int J Mol Med 2004, 13:915-922.

38. Yeste-Velasco M, Folch J, Casadesus G, Smith MA. Pallas M, Camins A: Neuroprotection by c-Jun NH2-terminal kinase inhibitor SP600125 against potassium deprivation-induced apoptosis involves the Akt pathway and inhibition of cell cycle reentry. Neuroscience 2009, 159:1135-1147.

39. Yu C, Minemoto Y, Zhang J, Liu J, Tang F, Bui TN, Xiang J, Lin A: JNK suppresses apoptosis via phosphorylation of the proapoptotic $\mathrm{BCl}-2$ family protein BAD. Mol Cell 2004, 13:329-340.

doi:10.1186/1472-6882-14-358

Cite this article as: Huang et al:: Protective effect of Danggui (Radix Angelicae Sinensis) on angiotensin II-induced apoptosis in $\mathrm{H} 9 \mathrm{c} 2$ cardiomyoblast cells. BMC Complementary and Alternative Medicine 2014 14:358. 